\title{
PARA REPENSAR O DIREITO: AS CONTRIBUIÇÕES DE HABERMAS E LUKÁCS PARA REFLETIR OS FUNDAMENTOS E O PAPEL DO DIREITO NA SOCIEDADE CONTEMPORÂNEA.
}

\author{
Lucas Santos de Almeida ${ }^{1}$ \\ José Marcos Miné Vanzella ${ }^{2}$
}

Resumo: O presente trabalho insere-se na temática da filosofia do direito. Tem por objetivo propor elementos para contribuir com o repensar do direito a partir da metodologia dialética de pesquisa bibliográfica. Tendo como base, por um lado as reflexões filosóficas atinentes ao conceito de direito e de democracia, bem como suas interações recíprocas propostas por Jürgen Habermas. Perfaz-se, por outro lado, um cotejo com a análise materialista dialética que afirma a contribuição do direito para a continuidade e existência do sistema econômico, realizada pelo filósofo György Lukács.

Palavras-chave: Direito. Democracia. Sociedade Contemporânea. Habermas. Lukács.

\section{TO RETHINK THE LAW: THE CONTRIBUTIONS OF HABERMAS AND LUKÁCS TO REFLECT THE FOUNDATIONS AND THE ROLE OF LAW IN THE CONTEMPORARY SOCIETY.}

\begin{abstract}
The present work is part of the philosophy of law. It aims to propose elements to contribute with the rethink of the right from the dialectical methodology of bibliographical research. Based on, on the one hand, philosophical reflections on the concept of law and democracy, as well as their reciprocal interactions proposed by Jürgen Habermas. On the other hand, a comparison is made with the dialectical materialist analysis that affirms the contribution of the right to the continuity and existence of the economic system, realized by the philosopher György Lukács.
\end{abstract}

Keywords: Law. Democracy. Contemporary Society. Habermas. Lukács.

\footnotetext{
${ }^{1}$ Mestre em Direito, com área de concentração em Concretização dos Direitos Sociais, Difusos e Coletivos, pelo Centro Universitário Salesiano de São Paulo - UNISAL, U. E. de Lorena (2017). Especialista em Direito Previdenciário e Direito do Trabalho, pela Escola Superior de Advocacia da OAB/SP (2017). Bacharel em Direito, pela Universidade do Vale do Paraíba - UNIVAP (2014). Membro do Grupo de Pesquisa Ética e Direitos Fundamentais, do UNISAL.

${ }^{2}$ Possui graduação em FILOSOFIA pela Faculdade Salesiana de Filosofia, Ciências e Letras de Lorena (1986), graduação em GEOGRAFIA pela Faculdade Salesiana de Filosofia, Ciências e Letras de Lorena (1989), MESTRADO EM FILOSOFIA pela Universidade Gama Filho (1998) e DOUTORADO EM FILOSOFIA pela Universidade Gama Filho (2005). Atualmente é professor efetivo do CENTRO UNIVERSITARIO SALESIANO DE SÃO PAULO e efetivo da FACULDADE DEHONIANA.
}

Revista Brasileira de Filosofia do Direito| e-ISSN: 2526-012X| Porto Alegre | v. 4 | n. 2 |

p. 36 -56 | Jul/Dez. 2018 


\section{INTRODUÇÃO}

O mundo contemporâneo, por conta de sua crescente complexidade, vem apresentando ao cosmos jurídico sensíveis desafios, os quais, além de estremecerem os postulados clássicos do positivismo (Autor, 2010), acabam por compelir, não só os profissionais da área jurídica, mas toda a sociedade, a repensar o papel do direito na realidade contemporânea, reformulando-o em todas suas dimensões.

Hodiernamente, muito se fala de pós-modernidade, um novo período históricomundial. Contudo, o próprio vocábulo "pós-modernidade" ainda indica uma fase de transição, um projeto, ou melhor, um processo de rompimento ou superação inacabado, porquanto o próprio prefixo "pós"3 está jungido à "modernidade", em dependência desta última no plano semântico (Autor, 2015, p. 37 - 40).

Assim, imbricando-se em um amplo contexto que suscita variadas indagações, o presente estudo, versado na filosofia do direito, ambiciona promover reflexões propedêuticas, interdisciplinares e críticas acerca do conceito de direito e democracia, sempre vislumbrados em suas interações recíprocas, mediante os postulados teóricos do filósofo e sociólogo alemão Jürgen Habermas (1929 - ), e procedendo, sobretudo, a um cotejo teórico com as proposições antitéticas e cronologicamente anteriores depreendidas da obra do filósofo húngaro György Lukács (1885 - 1971), ícone do marxismo ocidental. Questiona: como os pensamentos de Habermas e Lukács podem contribuir para repensar o direito?

Tem por objetivo propor elementos para contribuir com o repesar do direito a partir da dialética de sua compreensão: como locus privilegiado da interação e do entrelaçamento comunicativo, e como complexo social que contribui para a continuidade e existência do sistema econômico.

Tendo em vista o diálogo ora ofertado entre ambos pensadores, verifica-se o dialético confronto de ideias, enriquecendo-se a reflexão jusfilosófica no que tange à esfera jurídica, uma vez que, notadamente, acaba por se abandonar o paradigma tacanho e monocromático que tende a reproduzir um marco teórico uníssono e linear como verdade absoluta, fechada e presa em si mesma.

\footnotetext{
3 “[...] Expressões formadas com 'pós' não esgotam o espectro das atitudes em relação a um passado do qual se quer distanciar.". Autor, 2015, p. 40.
}

Revista Brasileira de Filosofia do Direito| e-ISSN: 2526-012X| Porto Alegre | v. 4 | n. 2 |

p. $36-56$ | Jul/Dez. 2018 
A fim de viabilizar este estudo, foram utilizados artigos científicos afetos ao tema, obras fundamentais de Habermas e Lukács, além de oportunas glosas marginais provenientes de outros pensadores.

A metodologia utilizada é, portanto, a pesquisa de documentação indireta, de cunho bibliográfico, contemplando o método dialético, visto que se configura, no presente artigo, a convergência e simultânea divergência de ideias e propostas de compreensão do cosmos jurídico-democrático, que é multidimensional e complexo, conforme salientado pelo desenvolvimento subsequente.

\section{ESCORÇO BIOGRÁFICO}

\subsection{JÜRGEN HABERMAS}

O filósofo e sociólogo alemão Jürgen Habermas nasceu em Dusseldorf, em 18 de junho de 1929, tendo se enveredado, desde muito cedo, por estudos em múltiplas searas do saber humano, tais como filosofia, história, economia e literatura alemã nas Universidades de Göttingen, Zurique e Bonn, galgando o doutorado no ano de 1954, mediante a tese $O$ Absoluto na História - Um Estudo sobre a Filosofia das Idades do Mundo, de Schelling (Autor, 1980, p. 9).

Em 1961, na Universidade de Marburgo, obteve seu título de livre-docência com sua notória tese Mudança estrutural da esfera pública ${ }^{4}$ (Autor, 2010, p. 782).

Conforme confessam Autor e Autor (1980, p. 10), o "nome de Habermas está intimamente associado ao da Escola de Frankfurt", algo ainda mais solidificado após a morte de Theodor Adorno, Max Hokheimer e Herbert Marcuse, fundadores da indigitada instituição,

\footnotetext{
4 "A mudança estrutural da esfera pública" dispõe de "sete capítulos subdivididos num total de 25 seções. $\mathrm{Na}$ introdução, considerada na obra como um capítulo", Habermas ambiciona demonstrar que "existe uma multiplicidade de vozes diferentes para os significados de 'público' e de 'esfera pública'. Ele alerta que muitos são os sentidos emitidos quando se fala de algo 'público'. Habermas esclarece que uma análise histórico-sociológica do rol de significados de tais termos poderia canalizar as diversas camadas verbais históricas até seu conceito sociológico. Importante esclarecimento o autor proporciona ao elucidar que as categorias 'público' e 'privado' são de origem grega e nos foram transmitidas ao longo da Idade Média, dentro dos preceitos do direito romano. Nesse viés histórico, as categorias de público e privado só passaram a ter uma efetiva aplicação processual jurídica com o surgimento do Estado moderno.". Autor, 2010.
}

Revista Brasileira de Filosofia do Direito| e-ISSN: 2526-012X| Porto Alegre | v. 4 | n. 2 |

p. $36-56$ | Jul/Dez. 2018 
sendo, no mundo contemporâneo, considerado como o "último representante" da escola da teoria crítica ${ }^{5}$.

Devido ao seu vínculo com a teoria crítica, fica esposado no presente trabalho seu diálogo com um dos maiores influenciadores, e, em certa medida, também fundador do Instituto de Pesquisa Social (Institute for Social Research), gênese da escola de pensamento mencionada, o filósofo húngaro György Lukács (MARCUS; TAR, 1984).

\subsection{GYÖRGY LUKÁCS}

Proveniente de uma rica família judia, o filósofo húngaro György Lukács ${ }^{6}$ nasceu em 13 de abril de 1885, na cidade de Budapeste.

Jovem talentoso, primeiramente, doutorou-se em Ciências Jurídicas pela Universidade de Budapeste, tendo concluído o doutorado em Filosofia logo em seguida, pela mesma instituição de ensino.

Em História e consciência de classe, publicado em 1923 e considerado seu livro mais célebre, foi desde o início alvo de muitas críticas de pensadores integrantes de variadas correntes, tendo sido, inclusive, denunciado no V Congresso da Terceira Internacional, em Moscou, considerado como revisionista (Autor, 2010).

Com mais de 30 livros e milhares de artigos e ensaios escritos, a trajetória de Lukács é uma mescla de ativismo político e dedicação acadêmica, tendo esta última ganhado força após os percalços sofridos na política e também no Partido Comunista Húngaro, em decorrência das perseguições dogmáticas empreendidas pelos próceres do stalinismo ${ }^{7}$.

\section{A OBRA DE HABERMAS: LINEAMENTOS}

\footnotetext{
${ }^{5}$ Segundo Autor, a teoria crítica da sociedade é aquela "proposta e desenvolvida pela Escola de Frankfurt, contrária ao tipo de trabalho da sociologia empírica americana", sendo, portanto, avessa à sociologia atrelada a "pesquisas setoriais e especializadas", primando pela "sociedade como um todo", analisando-se a sociedade sob o prisma de várias dimensões da sociabilidade humana. Autor, 2006. v. 6, p. 470.

${ }^{6}$ Nas palavras de Mascaro, a "vida pessoal de Lukács é inseparável de sua filosofia". Autor, 2012, p. 529.

7 GEORG LUKÁCS ARCHIVE. Marxist Internet Archive. Disponível em: <https://www.marxists.org/glossary/people//u.htm\#lukacs-georg>. Acesso em: 02 jun. 2017.
} 
Autor (2012) elucida que na obra de Habermas é possível depreender dois grandes momentos intelectuais que compõem um todo unitário, entretanto, imprescindíveis para compreender sua evolução intelectual, viabilizando um estudo detalhado de seus postulados e de sua produção bibliográfica.

O primeiro, compreendido até o final da década de sessenta, está notadamente haurido de elementos hegelianos e marxistas, especialmente em decorrência de seu intercâmbio intelectual realizado com os teóricos da crítica, fundadores da Escola de Frankfurt (Autor, 2006; Autor, 2012).

Já o segundo, subsequente àquele outro, representa uma linguistic turn, ou seja, uma virada linguística em suas próprias proposições, refinando sua propositura inicial e aproximando-se da obra de pensadores neopositivistas e liberais, muitos adeptos do pragmatismo filosófico anglo-saxão, em detrimento da influência primeva que sofreu sob o marxismo ocidental, junto com os fundadores da escola da teoria crítica (Autor, 2012, p. 358).

\subsection{TEORIA DO AGIR COMUNICATIVO}

A teoria do agir comunicativo é considerada o clímax da obra habermasiana, consubstanciada e reconhecida de modo sistematizado somente após a célebre linguistic turn configurada na trajetória de Habermas, em meados da década de setenta, a partir de quando passou a direcionar suas preocupações para a dimensão dialógica da sociedade enquanto categoria dotada de força sobrepujante (Autor, 2006; Autor, 2012).

Além do aspecto meramente analítico, a teoria do agir comunicativo carreia consigo uma grande carga valorativa, eminentemente ética, a fim de, mediante uma proposta de aprofundamento da interação consensual da sociedade, penetrar e concretizar o desiderato democrático, historicamente construído.

Segundo Autor (2013, p. 153), a teoria do agir comunicativo é calcada na racionalidade dialógica, sendo considerada como aquela que:

[...] se fundamenta no conceito de ação, entendida como a capacidade que os sujeitos sociais têm de interagirem intra e entre grupos, perseguindo racionalmente objetivos que podem ser conhecidos pela observação do próprio agente da ação. Habermas vai priorizar, para a

Revista Brasileira de Filosofia do Direito| e-ISSN: 2526-012X| Porto Alegre | v. 4 | n. 2 |

p. $36-56$ | Jul/Dez. 2018 
compreensão do ser humano em sociedade, as ações de natureza comunicativa. Isto é, as ações referentes à intervenção no diálogo entre vários sujeitos.

Nesse sentido, em consonância à glosa de Autor (2012, p. 360), ausculta-se quão emblemática é a função da interação comunicacional entre os indivíduos, in verbis:

[...] é a interação comunicacional entre os indivíduos, a partir de um mundo da vida - isto é, de certas relações culturais estruturadas dos homens entre si, em relação ao grupo social e mesmo em relação à produção e à natureza -, que se constrói o espaço basilar da própria sociabilidade. As referências, as possibilidades linguísticas, a cultura, todo esse complexo se levanta, dialeticamente da própria interação comunicacional.

De modo geral, vislumbra-se que a ação comunicativa, caracterizada pelo dinamismo entre "falantes e ouvintes" (Autor, 2013, p. 9) - os interlocutores -, compõe e reverbera seus efeitos em muitas dimensões da sociabilidade humana, isto é, no mundo da vida, uma das “categorias habermasianas fundamentais" (Autor, 2013, p. 153).

O mundo da $v i_{a}{ }^{8}$, cabe aqui registrar, deve sempre ser entendido como uma "espécie de recorte situacional e temático que é promovido a partir das ações das pessoas" na sociedade, considerando-se sempre "os horizontes de possibilidades à frente" (Autor, 2013, p. 9).

O conceito de mundo da vida - "complementar ao conceito de ação comunicativa" (Autor, 2013, p. 154), vez que esta última ocorre sempre naquela primeira - é, portanto, um "pano de fundo" no qual "padrões de interpretação" são linguisticamente organizados e transmitidos pela e na própria cultura (Autor, 2013, p. 9), respeitando-se os condicionantes que atuam em conjunto, de modo recíproco e interativo, quais sejam: (i) a dimensão subjetiva (personalidade de cada indivíduo), (ii) a dimensão normativa (os regramentos da sociedade), e

\footnotetext{
8 Autor chega a chamar atenção à particularidade apresentada pelo mundo da vida habermasiano. Em suas palavras, imperioso rememorar que o "mundo da vida está presente na construção de outros teóricos, mas Habermas trabalha, operacionaliza e interpreta tal conceito de maneira bem distinta da que foi feita por outros pensadores", porquanto salienta o entrecruzamento das dimensões da sociabilidade humana - já elencadas no corpo do texto -, alijando qualquer inadvertida inferência que confira proeminência a uma delas. A dimensão subjetiva, a dimensão normativa e a dimensão objetiva operam, assim, em sincronicidade indissociável, estando proscrita qualquer unilateralidade. Autor, 2013.
} 
(iii) a dimensão objetiva (consenso ou entendimento proporcionado pelo ambiente cultural comum), as quais se interpenetram, conjugando-se uma à outra (Autor, 2013).

Outro conceito imprescindível à escorreita compreensão do pensamento habermasiano, bem como, de modo indireto, à adequada colocação do agir comunicativo - o qual "atribui às forças ilocucionárias da linguagem orientada ao entendimento a função importante da coordenação da ação" (Autor, 1997a, p. 25) -, é a questão da esfera pública, que, por seu turno, encontra gênese na primeira grande obra do filósofo alemão, qual seja: Mudança Estrutural da Esfera Pública (Autor, 2009, p. 38), acompanhando-o até os dias atuais.

Segundo Autor (2009, p. 38), desde aquela ocasião, Habermas aprimorou a sistemática do referido conceito, especialmente após as contribuições de alguns de seus críticos, contudo, o cerne da esfera pública permanece o mesmo.

A esfera pública burguesa (Autor, 2009, p. 38 - 39) é sempre:

[...] uma categoria típica de uma época e não pode ser pensada ou deslocada para uma análise que fuja dos contextos da sociedade burguesa. Portanto, esfera pública está inicialmente limitada por seu caráter de categoria histórica. Aqui, a 'burguesia' é o suporte deste público, caracterizado fundamentalmente como o público que lê. Isto, somado ao surgimento da imprensa e outros fatores, cria as condições ideais para a formação de uma esfera na qual os sujeitos sejam capazes de construir e manifestar uma opinião sobre assuntos de interesse geral. Para Habermas um sujeito só faz parte de uma esfera pública enquanto portador de uma 'opinião pública'”.

Logo, a esfera pública é um "fenômeno social elementar", e não pode ser entendida como uma "instituição, nem como uma organização, pois ela não constitui uma estrutura normativa capaz de diferenciar entre competências e papéis, nem regula o modo de pertença a uma organização" (Autor, 1997b, p. 92). Não pode, também, ser considerada um sistema, porquanto acaba por caracterizar-se através dos "horizontes abertos, permeáveis e deslocáveis" (Autor, 1997b, p. 92).

É, por conseguinte, "uma estrutura comunicacional", "uma rede adequada para a comunicação de conteúdos, tomadas de posição e opiniões", reproduzindo-se "através do agir 
comunicativo", orientando-se pelo entendimento dialógico que emana e perpassa a sociedade (Autor, 1997b, p. 92, grifo do autor).

\subsection{DIREITO E DEMOCRACIA}

Para Habermas, as preocupações correspondentes ao direito estão intimamente vinculadas à noção de democracia, bem como todos seus imprescindíveis desdobramentos procedimentais.

O direito, imerso numa série de condicionantes procedimentais e administrativos, engloba a delicada noção de "iguais liberdades subjetivas de ação" dos integrantes de determinada sociedade, algo que no mundo hodierno é traduzido como direitos fundamentais, os quais, "enquanto direitos positivos, revestem-se de ameaças de sanções, podendo ser usados contra interesses opostos ou transgressões de normas” (Autor, 1997a, p. 170).

Neste diapasão, os direitos fundamentais, para serem assegurados, "pressupõem o poder de sanção de uma organização", o Estado, a única detentora do "emprego legítimo da coerção" (Autor, 1997a, p. 170), fazendo eco ao posicionamento anterior de Max Weber, segundo o qual o Estado detinha o "monopólio da violência física legítima” (Autor, 2013, p. 238), com vista a zelar e impor a concretização das normas jurídicas.

Assim, o Estado "mantém como reserva um poder militar" (Autor, 1997a, p.170), sendo indispensável enquanto "poder de organização, de sanção e de execução", uma vez que o mencionado sistema de direitos (direitos subjetivos) tem que ser concretizado na realidade concreta, só podendo ser viabilizado mediante uma estrutura administrativa organizada (Autor, 1997a, p. 171). Os direitos subjetivos, ou seja, as liberdades individuais, não podem ser estabelecidas de pronto, porquanto requerem um excurso organizacional, procedimental e burocrático.

Ademais, a sociedade "necessita de uma jurisdição organizada e de uma força para estabilizar" a dinâmica dos distintos atores sociais (Autor, 1997a, p. 171).

Mesmo diante da institucionalidade e da jurisdição bem organizadas, o Estado de Direito ainda é sondado pela aura da "desconfiança contra a razão falível e contra a natureza corruptível dos seres humanos", fazendo com que haja uma persistente "desconfiança não institucionalizável contra si mesmo", a fim de submeter as "formas legais" a uma vigilância moral (Autor, 2015, p. 138), algo apenas possível quando existe uma: 
[...] cultura política que dota as cidadãs e os cidadãos ao risco que são necessárias em situações transitórias e excepcionais a fim de reconhecer as violações à legitimidade e a fim de agir também ilegalmente por discernimento moral, em caso de necessidade. (Autor, 2015, p. $138-139){ }^{9}$

Entretanto, a despeito de sua deferência perante a necessidade de existência de um Estado para harmonização e coordenação da sociedade em ebulição, Habermas confessa que "a ideia segundo a qual o poder do Estado pode elevar-se acima das forças sociais como um pouvoir neutre sempre foi ideologia ${ }^{10 "}$ (Autor, 1997a, p. 219, grifo nosso), em prejuízo das tradicionais lições positivistas que, por sua vez, ditam que o Estado é um ente neutro e independente, acima e dissociado dos conflitos ínsitos à sociedade.

No âmbito do direito e da democracia, o princípio do discurso é um princípio habermasiano oniabrangente, que abarca todos os demais, e desfruta de duas acepções indispensáveis, ou melhor, dois sentidos, a saber: (i) sentido cognitivo (inicial, um filtro, "aceitabilidade racional" - "o procedimento democrático deve fundamentar a legitimidade do direito") e (ii) sentido prático ("relações de entendimento", "liberdade comunicativa" Arendt) (Autor, 1997a, p. 190 - 192).

Mister consignar que o aludido princípio do discurso "submete a validade de qualquer tipo de norma de ação ao assentimento daqueles que, na qualidade de atingidos, tomam parte em 'discursos racionais"', isto é, acaba-se por ser configurado um metaprincípio, notadamente oniabrangente, sob o qual encontram-se sistematizados todos os demais (Autor, 1997a, p. 1999).

No entanto, imperioso frisar, uma vez mais, que o direito desfruta de contundente vínculo com o cosmos estritamente político, sobre o qual reverbera, em grau de complementaridade, seus efeitos e propósitos. Nas próprias palavras de Autor (1997a, p. 211

\footnotetext{
9 Insere-se aqui, então, a questão da possibilidade da desobediência civil na ordem democrática. Segundo Habermas, diferentemente do rebelde ou resistente, "o infrator das regras só pode assumir o papel plebiscitário do cidadão que aparece como soberano imediato dentro dos limites de um apelo à maioria. [...] Ele reconhece a legalidade democrática da ordem existente. A possibilidade de justificar a desobediência civil resulta para ele somente da circunstância de que as regulações legais podem ser ilegítimas mesmo no Estado democrático de direito - no entanto, ilegítimas não segundo os critérios de uma moral privada qualquer, de um direito especial ou de um acesso privilegiado à verdade. São decisivos somente os princípios morais convincentes para todos.". Autor, 2015, p. 138.

${ }^{10} \mathrm{E}$ por que não rememorar, aqui, a oportuna análise de Pachukanis? Afinal, o "Estado não é apenas uma forma ideológica, ele é, ao mesmo tempo, uma forma de ser social. O caráter ideológico de um conceito não elimina aquelas relações reais e materiais que este exprime.". Autor, 2017, p. 89.
}

Revista Brasileira de Filosofia do Direito| e-ISSN: 2526-012X| Porto Alegre | v. 4 | n. 2 | 
- 212), depreende-se que: o "direito constitui o poder político e vice-versa; isso cria entre ambos um nexo que abre e perpetua a possibilidade latente de uma instrumentalização do direito para o emprego estratégico do poder”. Ou seja, é possível constatar a paulatina “institucionalização jurídica de rede de discursos e negociações” (Autor, 1997a, p. 212).

No direito, facticidade e validade "estão entrelaçadas" (Autor, 2015, p. 52), vezes estremecidas por tensões subjacentes, algo que reforça ainda mais a noção de que o direito compõe um contundente medium na sociabilidade humana.

Aliás, os "pressupostos comunicativos" devem sempre ser "admitidos factualmente por todos os participantes" que ingressarem em determinada argumentação", com anseios de "verdade ou validade" (Autor, 2015, p. 53, grifo do autor).

Autor (Autor, 2015, p. 53), apoiado em Habermas, chega mesmo a asseverar que "o direito se distingue de todos os meios sociais" devido ao fato de estar atrelado à "solidariedade", ao "dinheiro" e ao "poder", fator esse que também contribui para as eventuais tensões entre facticidade e validade, acima aventadas.

Não seriam, também, as "infrações civis às regras" (Autor, 2015, p. 140) um indício, mesmo que tênue, dessa tensão? Afinal, o "povo" é o "guardião da legitimidade" jurídicoestatal, conforme confessa o filósofo alemão (Autor, 2015, p. 141).

O Estado de Direito, ao explicitar uma série de "mecanismos de autocorreção" formais, procedimentais (legislativos, jurídicos etc.), só consegue reforçar o fato de que requer vigilância persistente, revisões constantes, devendo-se permitir, inclusive, outras novas "possibilidades de revisão", uma vez que "o direito e a política" estão em "adaptação e revisão constantes, como a marcha pioneira de correções atrasadas e inovações" (Autor, 2015, p. 140).

Essa multidimensionalidade e multifatorialidade da esfera jurídica é, de fato, um rompimento com a visão clássica do juspositivismo, que tem em Hans Kelsen seu representante máximo, segundo a qual o direito e Estado não podem ser estudados em conjunto.

\section{A OBRA DE LUKÁCS: LINEAMENTOS}

Lukács, tanto no âmbito da política, quanto no âmbito da filosofia, representa o desiderato inicial proposto pela Terceira Internacional, criada por Lênin, em 1919, a fim de

Revista Brasileira de Filosofia do Direito| e-ISSN: 2526-012X| Porto Alegre | v. 4 | n. 2 |

p. $36-56$ | Jul/Dez. 2018 
incentivar e disseminar a revolução socialista ao redor do globo, aprofundando a cientificidade do marxismo (Autor, 2006).

No plano filosófico, em oposição à corrente doutrinária propugnada pela Segunda Internacional, de viés kantiano, socorreu-se, uma vez mais, aos ensinamentos de Friedrich Hegel para aprofundamento dos estudos marxistas, algo vislumbrado especialmente em 1923, ano em que Lukács publicou sua notória e controversa obra História e consciência de classe, e Karl Korsch, Marxismo e filosofia, sendo ambos estudos considerados como marco na história do marxismo ocidental (Autor, 2006, p. 442).

\subsection{O DIREITO NA ONTOLOGIA DO SER SOCIAL}

Em seus anos finais, o longevo Lukács ainda estava insatisfeito com seu panorama bibliográfico, com suas conquistas e reflexões. Assim, empreendeu magnânimo esforço, não só intelectual, mas também físico, para redigir a maior obra de sua vida, que finalmente escrutasse a temática da ética sob uma apreciação marxista, algo até então inédito, dada a paralisia stalinista ${ }^{11}$ vigente na filosofia desde o final da década de vinte.

Entretanto, o filósofo húngaro viu-se impedido de adentrá-la sem antes apresentar imprescindíveis e exaustivas reflexões preliminares, de cunho estético e ontológico.

Nesse sentido, levando em consideração a obra de muitos pensadores - não apenas no âmbito da filosofia; não só de clássicos, mas também de atuais -, elaborou sua Estética ${ }^{12}$ e sua monumental Para uma ontologia do ser social ${ }^{13}$, acompanhada de seus correspondentes Prolegômenos, tendo, por derradeiro, permanecido apenas nos seus projetos oníricos a

\footnotetext{
11 Segundo Autor, "para Lukács, um dos fundamentos da paralisia teórica do marxismo residia justamente na liquidação da inspiração ontológica de Marx - não por acaso em algum lugar ele observou que muito do pensamento staliniano e stalinista expressava uma invasão neopositivista na tradição marxista". Autor, 2012, p. 13.

12 Segundo José Paulo Netto, Estética acaba por romper com "a esclerose do marxismo no seu trato rigoroso [...] da estética a partir de uma impostação ontológica”. Autor, 2012, p. 13.

${ }_{13}$ Nicolas Tertulian afirma que "[...] a Ontologia do ser social nasceu como pano de fundo de uma vasta pesquisa consagrada aos problemas da Ética. Depois de muitos anos de pesquisa [...], ele [Lukács] se dava conta de que não era possível estabelecer a especificidade da atividade ética fora de uma reflexão de conjunto, em contraposição aos componentes principais da vida da sociedade (economia, política, direito, religião, arte, filosofia): a Ontologia do ser social representa a concretização desse vasto programa totalizante, destinado a preparar a Ética (que infelizmente não virá a ser realizada).". Autor, 2010, p. 390.
}

Revista Brasileira de Filosofia do Direito | e-ISSN: 2526-012X| Porto Alegre | v. 4 | n. 2 |

p. $36-56$ | Jul/Dez. 2018 
redação e publicação de sua magnum opus que versaria sobre a ética, tão ansiada e rapidamente desvanecida devido ao agravamento de sua saúde e consequente falecimento ${ }^{14}$.

Em sua Para uma ontologia do ser social, Autor (2012, p. 28) assevera que, afinal, “objetivamente o ser social é a única esfera da realidade na qual a práxis cumpre o papel de conditio sine qua non na conservação e no movimento das objetividades, em sua reprodução e em seu desenvolvimento", e nesse panorama de profunda apreciação do ser social, salutar mencionar que, tendo em vista os postulados teóricos de tamanha reflexão, "ninguém se ocupou tão extensamente quanto Marx com a ontologia do ser social", pensador que, por seu turno, vislumbrou todas as "determinações categoriais" (Autor, 2012, p. 25 e 27), em dissonância ao pensamento que lhe antecedia e, inclusive, em grande medida lhe sucedeu.

Afinal, no que pese o empenho desprendido por vários filósofos, fica patente o quase total alijamento do "problema ontológico fundamental da especificidade ontológica do ser social" (Autor, 2012, p. 26), sem o qual queda preterida qualquer reflexão oniabrangente e verdadeiramente científica, dissociada de falácias positivistas, ideológicas.

Autor (2012, p. 32) começou por analisar a relevância da ontologia ao responder questões candentes da sociabilidade humana, algo que, primeiramente, foi intentado, já no medievo, pela ontologia religiosa capitaneada pela Igreja Católica, sendo que a indigitada ontologia "se move desde as necessidades de um comportamento diante da vida [...], e constrói uma imagem de mundo que, se efetiva, poderia constituir uma garantia para a realização daqueles desejos que se manifestam na necessidade religiosa".

Um pouco além da ontologia, o próprio Autor (2017), jurista soviético, chegou a refletir de modo semelhante, quando tecia algumas considerações acerca da superação histórica da ideologia religiosa, corroborando indiretamente a assertiva de Lukács, redigida muitos anos depois.

Em suas palavras:

O Estado jurídico é uma miragem, mas uma miragem totalmente conveniente para a burguesia, pois substitui a ideologia religiosa em decomposição e esconde das massas o domínio da burguesia. A ideologia do Estado jurídico é mais conveniente que a religiosa,

${ }^{14}$ Coube aos alunos de Lukács o prosseguimento de sua obra inconclusa e, inclusive, a redação da biografia do filósofo de Budapeste, ditada em entrevistas concedidas pouco antes de sua morte. Cf. Autor, 1999.

Revista Brasileira de Filosofia do Direito| e-ISSN: 2526-012X| Porto Alegre | v. 4 | n. 2 |

p. $36-56$ | Jul/Dez. 2018 
porque ela, além de não refletir a totalidade da realidade objetiva, ainda se apoia nela. A autoridade como 'vontade geral', como 'força do direito', na medida em que se realiza na sociedade burguesa representa um mercado. (Autor, 2017, p. 148).

Após Pachukanis, Lukács, dotado de notável capacidade de síntese, emaranhando-se na especificidade da esfera jurídica, esclareceu que o direito "só surge numa sociedade relativamente evoluída", haurida do arrebatador animus de "consolidar de modo consciente, sistemático, as relações de dominação, de regular as relações econômicas entre os homens", uma vez que, afinal, diferentemente da economia, "não visa produzir algo novo no âmbito material"; isto é, a "teleologia jurídica" (Autor, 2012, p. 386) decorre do "desenvolvimento econômico" (Autor, 2013, p. 247) de determinada sociedade, e requer, necessariamente, um "mundo material como existente", configurando-o conforme "princípios ordenadores obrigatórios, que esse mundo não poderia extrair de sua própria espontaneidade imanente" (Autor, 2012, p. 386).

Contudo, urge registrar que as peculiaridades do cosmos jurídico acabam por obnubilar as “conexões econômicas" refletidas em si mesmo. (Autor, 2013, p. 260).

Em Lukács, o direito, assim como toda superestrutura, não é mero “epifenômeno" da economia (Autor, 2013, p. 197), desfrutando de "autonomia relativa considerável com relação ao regime vigente em cada caso", ou seja, acaba até mesmo aparentando ser "uma espécie de Estado dentro do Estado", mas, em última instância, encontra-se fatidicamente jungido aos imperativos do capital, voltados à perpetuação da valorização do valor (autorreprodução exponencial do mais-valor), da troca mercantil etc. (Autor, 2013, p. 247).

Explica-se, então, a aventada autonomia dos complexos sociais, na medida em que:

[...] nenhum complexo poderia subsistir nem funcionar utilmente se não formasse em si mesmo os seus princípios e métodos específicos de ação, de organização etc. Essa autonomia de todo complexo social parcial [...] jamais poderá implicar independência em relação à estrutura [econômica] e à dinâmica do desenvolvimento do respectivo estágio da sociedade. (Autor, 2013, p. 213).

Percebe-se, portanto, que "quanto mais evoluída for uma sociedade”, maior será a autonomia do direito em face dos "diversos complexos sociais" que compõem a sociabilidade 
humana e com os quais se relaciona continuamente (Autor, 2013, p. 247), sendo salutar pontuar que, segundo Lukács, a proeminência da categoria trabalho não elimina a dinâmica própria de outros complexos sociais, como, verbi gratia, o direito, a política, a religião etc. (Autor, 2013).

O direito domina "a vida cotidiana dos homens no interesse de uma determinada classe" (Autor, 2013, p. 655), e pode, assim, ser considerado um "instrumento para fixar validamente o respectivo status quo econômico, visando que seu funcionamento se dê sem atritos". O direito é, portanto, o lubrificante necessário ao funcionamento das engrenagens econômicas elementares da sociedade de classes (Autor, 2013, p. 623).

Com o advento dos tempos modernos, das complicações do capitalismo em ebulição, o direito vai ganhando características semelhantes a transações bancárias, econômicas, dotadas de lógica previsível, fria e exata, perdido em si mesmo diante dos reclamos da sociedade.

Nas palavras de Autor (2013, p. 241):

Torna-se cada vez mais intensa necessidade social de que as consequências jurídicas de uma ação possam ser calculadas de antemão com a mesma exatidão que a própria transação econômica.

Nesse complexo panorama, o direito vai, aos poucos, distanciando-se ${ }^{15}$ mais e mais do "chão da realidade" em razão de sua progressiva tecnicidade, especificidade, pois "quanto mais elaborada for essa sistematização, tanto mais ela necessariamente se afastará da realidade" (Autor, 2013, p. 239).

O direito, tal como conhecido no mundo contemporâneo - técnico, positivo e sistematizado -, é um fenômeno burguês, sendo grande quimera nivelá-lo às configurações jurídicas pretéritas, decorrentes dos demais períodos histórico-mundiais (Autor, 2013; Autor, 2012).

Ademais, o fato de existirem sanções, ou melhor, "ameaça geral de punições" (Autor, 2013, p. 655), tão discutidas pela doutrina, para que sejam concretizados os comandos

${ }^{15}$ Eyguiéni B. Pachukanis, muitos anos antes de Lukács, asseverou quase o mesmo, quando comentava o juspositivismo. In verbis: "[...] O extremo formalismo da escola normativista (Kelsen) expressa, sem dúvida, a decadência geral do pensamento científico burguês corrente, que, ansioso por esgotar-se em métodos estéreis e artifícios lógicos formais, flerta com sua completa ruptura diante da realidade da vida". Autor, 2017, p. 85.

Revista Brasileira de Filosofia do Direito| e-ISSN: 2526-012X| Porto Alegre | v. 4 | n. 2 |

p. $36-56$ | Jul/Dez. 2018 
jurídicos, não implica que a coerção seja seu fôlego essencial, visto que vasta parcela da população precisa submeter-se voluntariamente ao direito, sob pena de tornar-se inócuo seu respectivo desiderato.

Em outras palavras,

[...] Cada uma dessas regulamentações pressupõe que a maneira prática do agir comum dos membros da sociedade siga 'voluntariamente', pelo menos externamente, essas prescrições; só diante de uma minoria relativamente pequena a coerção do direito deve e pode tornar-se de fato eficaz. (Autor, 2010, p. 43).

Nesse sentido, as profundas indagações geralmente suscitadas na filosofia e teoria geral do direito (conceito de direito, conceito de norma, conceito de proposição, sanção, validade, eficácia, legitimidade etc.) só podem ser corretamente abalizadas tendo em conta tais esclarecimentos críticos.

\section{A RECEPÇÃO DE LUKÁCS PELA OBRA HABERMASIANA}

Em sua magnum opus, publicada sob o título de Theorie dês Kommunikativen Handelns, de 1981, Habermas dedica longas passagens para dialogar com os postulados teórico-filosóficos de vários pensadores, sendo, um deles, Lukács.

No capítulo IV - "De Lukács a Adorno: Racionalização como reificação", Habermas aborda profundamente a temática da racionalização sob os vieses apresentados por determinados pensadores, especialmente no tocante aos fundadores da teoria crítica, destacando, inclusive, a influência weberiana em alguns dos postulados vislumbrados nas contribuições do marxismo ocidental.

Seu propósito é analisar a recepção marxista empreendida por Lukács, Horkheimer e Adorno em relação à teoria da racionalização de Weber. Em suas próprias palavras:

“[...] Investigarei a recepção marxista da teoria da racionalização weberiana por Lukács, Horkheimer e Adorno, para demonstrar logo a seguir, com base no andamento aporético da crítica da razão instrumental, de que maneira essa problemática fará ir pelos ares as fronteiras da filosofia da consciência." (Autor, 2012, p. 592).

Revista Brasileira de Filosofia do Direito| e-ISSN: 2526-012X| Porto Alegre | v. 4 | n. 2 |

p. $36-56$ | Jul/Dez. 2018 
Lukács, conforme prelecionado por Autor (2012, p. 628), ambicionava uma "reconstrução filosófica do marxismo" e, segundo o filósofo alemão, esse empreendimento implicou um "retorno ao idealismo objetivo" de Hegel, tendo os "pontos centrais" imergido nos postulados e pressupostos hegelianos.

Eis justamente o caso, quando Lukács faz questão de criticar a problemática da gnoseologia kantiana ${ }^{16}$, recorrendo, assim, à pretérita crítica que Hegel havia feito em relação a Kant para delinear sua nova análise (Autor, 2012, p. 621).

Segundo Autor (Autor, 2012, p. 622), a própria crítica kantiana, em consonância ao sistema do capital, "reflete apenas estruturas de consciência reificadas", uma vez que acaba por compor a "forma de [uma] mercadoria que se tornou universal". A lógica kantiana é, por conseguinte, a lógica da mercadoria.

A análise de Lukács, consoante à narrativa de Autor (2012, p. 613-614), parte justamente da "forma da mercadoria" encontrada em Marx, especialmente ao longo d' $O$ Capital, no qual se fala do "caráter de fetiche da mercadoria".

As transações que se dão no medium do valor de troca esquivam-se da intersubjetividade própria ao entendimento mútuo linguístico, transforma-se em algo que tem lugar no mundo objetivo, em pseudonatureza. À medida que o trabalhador assalariado, em toda sua existência, torna-se dependente do mercado, os processos de valoração anônimos invadem seu mundo da vida e vão destruindo a eticidade de uma intersubjetividade gerada por via comunicativa: e enquanto isso as relações sociais vão se transformando em relações puramente instrumentais. (Autor, 2012, p. 614).

Como preleciona Lukács, a reificação acaba por ser um estranhamento ${ }^{17}$, ou seja, "um processo" (Autor, 2013, p. 635), "um modo histórico-social da vida humana" (Autor, 2013, p. 626), e, também, um "fenômeno ideológico" que corrobora o status quo (Autor, 2013, p. 632), visto que:

${ }^{16}$ No fim de sua vida, Lukács fará questão de privilegiar totalmente a apreciação ontológica, em prejuízo da gnoseológica ou lógica. Cf. Autor, 2013. v. 2.

17 "Os desdobramentos analíticos oferecidos por Lukács em sua tematização sobre o estranhamento (Enifremdung), presentes na Ontologia do Ser Social, são, entre tantos outros exemplos, desenvolvimentos abrangentes e ampliados da teoria marxiana da alienação/estranhamento.". Autor, 1999, p. 158. 
O intercâmbio de mercadorias, a economia capitalista, a manipulação que dela mais tarde se originou, os seus respectivos reflexos ideológicos naturalmente produzem todo dia e toda hora reificações em massa. A sua forma econômica originária foi descrita pelo próprio Marx, que não deixou de referir-se ao seu modelo original, ao tratar das suas formas fenomênicas mais complexas. [...] A reificação que se reproduz continuamente é um momento importante no desenvolvimento da economia. (Autor, 2013, p. 683).

Afinal, no mundo contemporâneo, o mundo da vida ${ }^{18}$ - e esta, conforme já visto, é uma terminologia reiteradamente utilizada por Habermas em suas obras -, é fartamente reificado, ou seja, os atos e as relações humanas são vislumbrados "sob a forma de coisas", “entidades" manipuláveis desprovidas do dinamismo vital que, em verdade, possuem. As relações entre pessoas são contempladas como relações coisificadas, objetais (Autor, 2012, p. 612). As orientações estabelecidas pelo "valor de troca" furtam dos sujeitos sua correspondente subjetividade, reduzindo-os à mera "dimensão objetiva", instrumental, vindo a ferir qualquer eticidade (Autor, 2012, p. 617).

As "condições de vida comunicativas" são, portanto, reificadas em favor de uma "racionalidade cognitivo-instrumental", prejudicando-se qualquer "racionalidade prática" (Autor, 2012, p. 625).

Assim como partilhado por Weber e Hokheimer, Lukács expressa que em uma sociedade pautada pela "forma da mercadoria", "o mundo da vida tem de ser reificado", rebaixando fatalmente o indivíduo ao mundo da vida de uma sociedade "exterior a ele", autônoma, abstraída, densificada, até, então, "atingir a condição de um sistema opaco", conforme já previsto pela teoria dos sistemas (Autor, 2012, p. 620).

Contudo, diferentemente de Weber e Horkheimer, Lukács defende que não se pode impedir o indigitado desenvolvimento desenfreado da racionalização, da reificação, uma vez que esta, consubstanciada por uma "teoria da crise" formulada por Marx, deverá desenvolverse até "colidir com [suas próprias] barreiras internas" (Autor, 2012, p. 621).

Habermas faz questão de salientar que Lukács peca ao adicionar a "teoria da consciência de classes" à teoria da reificação (Autor, 2012, p. 626), a despeito de haver uma "realização peculiar" do filósofo de Budapeste, quando postula por "associar Marx e Weber

18 "A autonomização reificante do sujeito leva, desse modo, a uma dilaceração prático-ideal do processo da vida, que ontologicamente é sempre unitário.". Autor, 2013. v. 2, p. 683.

Revista Brasileira de Filosofia do Direito | e-ISSN: 2526-012X| Porto Alegre | v. 4 | n. 2 |

p. $36-56$ | Jul/Dez. 2018 
para poder considerar sob os dois aspectos ao mesmo tempo (da reificação e da racionalização) o desprendimento da esfera do trabalho social em relação a outros contextos do mundo da vida" (Autor, 2012, p. 617, grifo do autor).

De modo panorâmico, o cotejo entre a obra de ambos os autores revela que enquanto em Lukács a categoria trabalho desfruta de centralidade no ser social, em Habermas a categoria do trabalho é uma entre várias, restando ao agir comunicativo a proeminência ${ }^{19}$ (Autor, 1999).

A crítica que Habermas empreende acerca do conceito de reificação e fetichismo em Lukács é, segundo Autor (1999, p. 158), inapropriada, visto que:

A crítica de Habermas de que o fetichismo e a reificação em Marx ficam restritos à esfera do trabalho mas deveriam estender-se ao cidadão-consumidor também nos parece sem sustentação, a menos que raciocinemos a partir da disjunção habermasiana. Mas se essa disjunção é desprovida de fundamento, a crítica de Habermas torna-se também aqui irrealizada.

Evidentemente que, ao longo de sua apreciação, Habermas ${ }^{20}$ atém-se mais ao Lukács jovem $^{21}$, ainda eivado - conforme o próprio filósofo húngaro confessa em seu extemporâneo posfácio à História e consciência de classe - de muitos cacoetes realmente hegelianos, um tanto quanto idealistas.

Habermas, portanto, deixa de lado as superações teóricas levadas a cabo pelo Lukács tardio, justamente aquele que redigiu a monumental Para uma ontologia do ser social e ambicionou concluir a obra de toda sua vida.

Por derradeiro, conforme reflete Autor (1999, p. 161), no que pese a significativa distinção no tratamento oferecido, tanto Lukács quanto Habermas “conferem um papel central

19 "Habermas propugna, em sua análise sobre a sociedade contemporânea, que a centralidade do trabalho foi substituída pela centralidade da esfera comunicacional ou da intersubjetividade.". Autor, 1999, p. 146, grifo do autor.

${ }^{20}$ Cf. Autor, 2012. v. 2, p. 609.

21 "Evidencia-se aqui o limite da crítica habermasiana, ao afirmar que a teoria da reificação de Marx e Lukács confina-se à esfera do trabalho social e mostrar-se-ia por isso incapaz de incorporar também a esfera do consumo. Como vimos acima, com as indicações de Nicolas Tertulian, a incorporação lukacsiana da reificação é muito mais complexa e fértil, abrangente e ampliada, complexa e nuançada, do que sugere a crítica habermasiana. É verdade que Habermas não trata da obra lukacsiana da maturidade. Mas como ele critica tanto o Lukács de História e Consciência de Classe quanto o conjunto da obra marxiana, evidencia-se a improcedência da limitação apontada por Habermas à teoria (marxiana e marxista) da reificação.". Autor, 1999, p. 160, grifo do autor. 
à esfera da subjetividade, quer na gênese, quer no desenvolvimento e emancipação do ser social".

\section{CONCLUSÃO}

Conforme delineado no presente trabalho, verificou-se que o direito, em face dos difíceis dilemas infligidos ao mundo contemporâneo, pode ser vislumbrado por diferenciadas dimensões e ênfases.

Foram delineadas duas vertentes jusfilosóficas: o direito enquanto locus privilegiado do agir comunicativo depreendido da obra habermasiana, e o direito enquanto espelhamento e configuração necessária do sistema econômico, devidamente detalhado nos estudos do Lukács tardio.

Seja como locus privilegiado da interação e do entrelaçamento comunicativo, seja como complexo social que contribui para a continuidade e existência do sistema econômico, urgente é a mudança de postura por parte dos juristas e de toda sociedade, a fim de repensar a verdadeira natureza da esfera jurídica, bem como seu funcionamento e interação com outras dimensões da sociabilidade humana.

Por óbvio, a reconstrução ética do direito, que deverá mediar tanto os apetites econômicos quanto os reclamos sociais dos diversos atores sociais, só é possível mediante as lentes habermasianas, voltadas à eticidade que emana do agir comunicativo, pautado pelo consenso racional da sociedade, visto que em Lukács o direito, assim como o sistema do capital como um todo, não deve e não pode ser reconstruído - algo que concatenaria num revisionismo condescendente -, mas sim, superado, suprassumido (aufhebung) pela sociedade pós-capitalista, que remeterá direito e Estado às antiquarias de um passado pré-histórico.

Independentemente da postura a ser tomada ou eligida pelo estuidoso, o indicado diálogo teórico procedido por Habermas em face de Lukács, apesar de discordâncias e críticas delineadas ao filósofo húngaro, também implica certa convergência de ideias no tocante a vários aspectos do fenômeno do fetichismo e da reificação do mundo da vida, algo que, por seu turno, inviabiliza uma realização plena e dignificante dos seres humanos em um mundo verdadeiramente democrático.

Revista Brasileira de Filosofia do Direito| e-ISSN: 2526-012X| Porto Alegre | v. 4 | n. 2 |

p. $36-56$ | Jul/Dez. 2018 


\section{REFERÊNCIAS}

ALVES, Alaôr Caffé. Dialética e direito: linguagem, sentido e realidade. Barueri: Manole, 2010.

ANTUNES, Ricardo. Os sentidos do trabalho: ensaio sobre a afirmação e a negação do trabalho. São Paulo: Boitempo, 1999.

DUAYER, Mario; SIQUEIRA, Andrea Vieira; ESCURRA, María Fernanda. A ontologia de Lukács e a restauração da crítica ontológica em Marx. Pesquisa Teórica, Florianópolis, v. 16, n. $1, \quad$ p. 17-25, jan./jun. 2013. Disponível em: <http://www.scielo.br/pdf/rk/v16n1/v16n1a03.pdf>. Acesso em: 16 maio 2017.

FREITAG, Bárbara; ROUANET, Sergio Paulo (orgs.). Habermas. São Paulo: Ática, 1980.

GEORG LUKÁCS ARCHIVE. Marxist Internet Archive. Disponível em: <https://www.marxists.org/glossary/people/l/u.htm\#lukacs-georg>. Acesso em: 02 jun. 2017.

GUTIERREZ, Gustavo Luis; ALMEIDA, Marco Antonio Bettine de. Teoria da ação comunicativa (Habermas): estrutura, fundamentos e implicações do modelo. Veritas, Porto Alegre, v. 58, n. 1, p. 151 - 173, jan./abr. 2013. Disponível em: <http://www.producao.usp.br/bitstream/handle/BDPI/45747/teoria\%20da\%20a\%C3\%A7\%C3 $\%$ A3o\%20comuinicativa\%20\%28habermas\%29\%20-

$\% 20$ estrutura $\% 2 \mathrm{C} \% 20$ fundamentos $\% 20 \mathrm{e} \% 20 \mathrm{implica} \% \mathrm{C} 3 \% \mathrm{~A} 7 \% \mathrm{C} 3 \% \mathrm{~B} 5 \mathrm{es} \% 20 \mathrm{do} \% 20 \mathrm{model}$ o.pdf? sequence $=1 \&$ isAllowed=y>. Acesso em: 12 jun. 2017.

HABERMAS, Jürgen. Direito e democracia: entre facticidade e validade. Trad. de Flávio Beno Siebeneichler. Rio de Janeiro: Tempo Brasileiro, 1997a. v. 1.

Direito e democracia: entre facticidade e validade. Tras. De Flávio Beno Siebeneichler. Rio de Janeiro, Tempo Brasileiro, 1997b, v. 2.

Unesp, 2015.

A nova obscuridade: pequenos escritos políticos V. Trad. de Luiz Repa. São Paulo:

Teoria do agir comunicativo: sobre a crítica da razão funcionalista. Trad. de Flávio Beno Siebeneichler. São Paulo: Martins Fontes, 2012. v. 2.

LOSEKANN, Cristiana. A esfera pública habermasiana, seus principais críticos e as possibilidades de uso deste conceito no contexto brasileiro. Pensamento Plural, Pelotas, n. 4, p. 37-57, jan./jun. 2009. Disponível <https://periodicos.ufpel.edu.br/ojs2/index.php/pensamentoplural/issue/view/285/showToc>. Acesso em: 07 jun. 2017.

Revista Brasileira de Filosofia do Direito| e-ISSN: 2526-012X| Porto Alegre | v. 4 | n. 2 |

p. $36-56$ | Jul/Dez. 2018 
LUKÁCS, György. Pensamento vivido: entrevista a István Eörsi e Erzsébet Vezér. Trad. de C. A. Franco. Viçosa: Ad Hominem, 1999.

Prolegômenos para uma ontologia do ser social: questões de princípios para uma ontologia hoje tornada possível. Trad. de Lya Luft e Rodnei Nascimento. Boitempo: São Paulo, 2010.

Para uma ontologia do ser social I. Trad. de Carlos Nelson Coutinho, Mario Duayer e Nélio Schneider. São Paulo: Boitempo, 2012. v. 1.

Para uma ontologia do ser social II. Trad. de Nélio Schneider, Ivo Tonet e Ronaldo Vielmi Fortes. São Paulo: Boitempo, 2013. v. 2.

MARCUS, Judith; TAR, Zoltan (orgs.). Foundations of the Frankfurt School of Social Research. New Burnswick: Transaction, 1984.

MASCARO, Alysson Leandro. Filosofia do Direito. 2. ed. São Paulo: Atlas, 2012.

OLIVEIRA, Vânia Aparecida Rezende. Mudança estrutural da esfera pública: investigações quanto a uma categoria da sociedade burguesa. Cadernos EBAPE.BR, Rio de Janeiro, v. 8, n. 4, p. $782-788$, dez. 2010.

PACHUKANIS, Evguiéni B.. Teoria geral do direito e marxismo. Trad. de Paula Vaz de Almeida. São Paulo: Boitempo, 2017.

PALERMO, Luis Claudio. A importância da teoria do agir comunicativo na atualidade: racionalidade, mundo da vida e democracia deliberativa. Revista Eletrônica de Humanidades do Curso de Ciências Sociais da UNIFAP, Macapá, n. 6, p. 01-17, dez. 2013. Disponível em: $<\quad$ https://periodicos.unifap.br/index.php/pracs/article/viewFile/806/n6Palermo.pdf $>$. Acesso em: 04 jun. 2017.

REALE, Giovanni; ANTISERI, Dario. História da filosofia: de Nietzsche à Escola de Frankfurt. Trad. de Ivo Storniolo. São Paulo: Paulus, 2006. v. 6.

VANZELLA, José Marcos Miné. Valores constitucionais de cidadania, identidade, reconhecimento e efetivação dos direitos. In: jurídica. Campinas: Alínea, 2015, p. 51 - 65. (org.). A dialética entre valores e forma 